\title{
Relation of photosensitivity to epileptic syndromes
}

\author{
P WOLF,* R GOOSSES \\ Abteilung für Neurologie, Klinikum Charlottenburg der Freien Universität, Berlin, Federal Republic of Germany
}

SUMMARY Photosensitivity is the most common mode of seizure precipitation. It is age-related, more frequent in females, and most often found in generalised epilepsies. Little is known about its relation to individual epileptic syndromes. This study on 1062 epileptic patients who had 4007 split screen video EEG investigations revealed that the relation to generalised epilepsy is even more close than generally believed. Versive seizures with visual hallucinations was the only focal seizure type related to photosensitivity. Of the syndromes of generalised epilepsy, only childhood absence epilepsy, juvenile myoclonic epilepsy, and epilepsy with grand mal on awakening were related to photosensitivity. The closest correlation was with juvenile myoclonic epilepsy. This is confirmed by a relation to the poly-spike wave pattern, and by an increase of myoclonic seizures by intermittent light stimuli. No relation was found with early childhood syndromes of generalised epilepsy, or generalised tonic-clonic seizures in the evening, or, most remarkably, with juvenile absence epilepsy. In generalised epilepsies with onset around puberty, photosensitivity could thus act as a pathoplastic factor. The female preponderance in both childhood absences and photosensitivity could be due to the same unknown factor.

Photosensitivity does not necessarily signify epilepsy. ${ }^{1}$ In connection with epilepsy, photosensitivity is the most common mode of sensory seizure precipitation. The literature on this subject is extensive, covers many aspects, and has been reviewed repeatedly. ${ }^{1-4}$ Some questions, however, are still open. Thus, in recent years the opinion prevails that photosensitivity is related to generalised rather than localised epilepsies but little is known about its relation to more specific syndromatic entities. These are the subject of the present study.

\section{Material and methods}

The study is based on all EEGs of epileptic patients who were registered in our video EEG laboratory in the period 1 January 1974 to 31 May 1982. Photic stimulation and video recordings were routine.

A stroboscope with a clear glass and a flash luminance of 750.000 lux (measured at $1 \mathrm{~m}$ distance at the point of maximal illumination) was used in frontal position at $50 \mathrm{~cm}$ from the eyes thus subtending a visual angle of about $14^{\circ}$. Flashes

\footnotetext{
*Present address and address for reprint requests: Professor Dr $\mathrm{P}$ Wolf, Epilepsie-Zentrum Bethel, Klinik für Anfallskranke Mara I, Maraweg 21, D-4800 Bielefeld 13, F.D.G.
}

Received 25 September 1984 and in revised form 7 January 1986. Accepted 15 February 1986 of increasing and decreasing frequency from 3 to $30 \mathrm{~Hz}$ were applied. In equivocal cases, stimulation blocks at various constant flash frequencies, and irregular flash sequences were added. The patients were repeatedly asked to open and close their eyes at variable flash rates.

A diagnosis of photosensitivity required the precipitation of a clinical seizure or spike waves, poly-spike waves or repetitive spikes of a frequency independent of the flash rate. Precipitation of such discharge was assumed if it appeared de novo during photostimulation. If epileptic discharge had already been present in the unprovoked EEG, precipitation was assumed if two of the following conditions were fulfilled: threefold or more increase compared with the 2 minutes of highest discharge density in the unprovoked EEG, changing phenotype compared with baseline, or repeated correlation of discharge to eye closure during photo-stimulation. De novo appearance of flash rate dependent discharge and generalised slow rhythms as well as doubtful increase of epileptic discharge was considered as suspicious of photosensitivity. All other phenomena including the "photomyoclonic response" of Bickford" or "photomyogenic response" of Rabending and $\mathrm{Klepel}^{3}$ were ignored.

All EEGs had been evaluated by the first author or under his personal supervision, using identical criteria throughout the study period. If these were not clearly stated in the description, the original EEG was re-evaluated by the first author. There were 4007 EEGs of 1062 patients. These were assigned to one of three groups: patients without epileptic discharge $(n=596)$, non-photosensitive patients with epi- 
leptic discharge $(\mathrm{n}=345)$, and photosensitive patients $(\mathrm{n}=103)$.

In 18 patients, there was a suspicion of photosensitivity that could neither be confirmed nor refuted. These were excluded from the study. The mean age at first EEG investigation of these patients ( 31.3 years) was higher than that of unequivocally photosensitive subjects (21.9 years). Their diagnostic ambiguity was not explained by a smaller number of investigations ( 5.3 as compared with 5.8 in photosensitive subjects and 5.4 in non-photosensitive patients with epileptic discharge). On the other hand, a negative EEG finding could be influenced by the number of investigations (mean of 2.5 in this group of patients).

The three groups classified were compared with a series of clinical and EEG data, and the syndrome diagnosed according to the International Classification of Epilepsies and Epileptic Syndromes. ${ }^{6}$

1 Localisation-related epilepsies and other epilepsies with focal seizures,

2 Generalised idiopathic and/or symptomatic epilepsies (West and Lennox-Gastaut-syndromes).

3 Childhood absence epilepsy (pyknolepsy) with or without generalised tonic-clonic seizures but without myoclonic seizures.

4 Juvenile absence epilepsy with or without generalised tonic-clonic seizures but without myoclonic seizures.

5 Juvenile myoclonic epilepsy with or without absences or generalised tonic-clonic seizures.

In addition, all patients with generalised tonic-clonic seizures (alone or associated with minor seizures) were considered separately according to their relation to the sleep-wake-cycle distinguishing four groups:

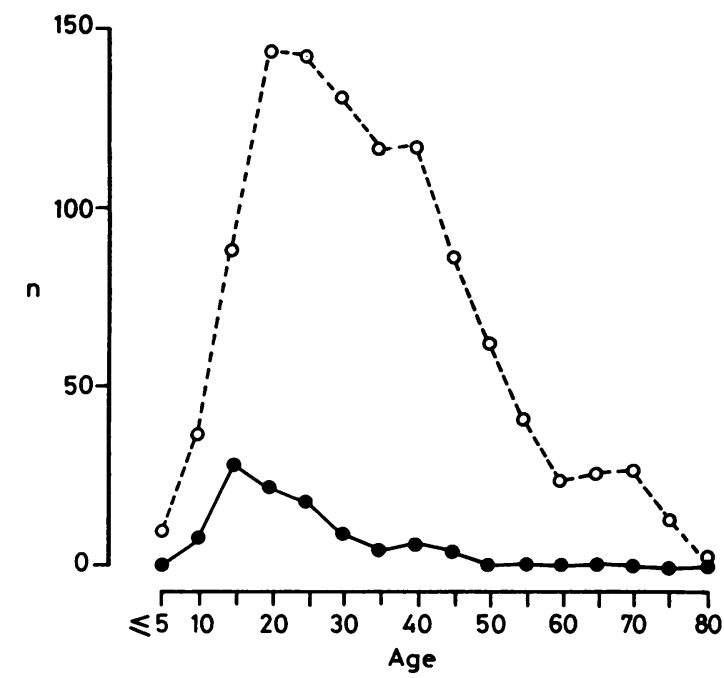

Fig Age at first investigation in our EEG video laboratory. Mean age of photosensitive patients was 21.9 years $(S D \pm 11 \cdot 2)$, of non-photosensitive patients $33 \cdot 1$ years ( $S D \pm 15 \cdot 4)$. The difference is significant $(p<0.001)$. Thin line, all epileptic patients $(n=1062)$. Thick line,

photosensitive patients $(n=103)$.
Table 1 Photosensitivity and age of onset of epilepsy

Mean age in years $(S D$

\begin{tabular}{ll}
\hline Photosensitive subjects & $14 \cdot 4 \pm 5 \cdot 1$ \\
Non-photosensitive subjects & $19 \cdot 9 \pm 7 \cdot 6^{*}$ \\
- with epileptic discharge & $16 \cdot 0 \pm 7 \cdot 1$ \\
- without epileptic discharge & $22 \cdot 2 \pm 7 \cdot 7 \dagger$ \\
\hline
\end{tabular}

Significant differences from photosensitive subjects, ${ }^{*} p<0.01$; $+p<0.001$.

1 generalised tonic-clonic seizures on awakening,

2 generalised tonic-clonic seizures in the evening leisure,

3 generalised tonic-clonic seizures during sleep,

4 generalised tonic-clonic seizures of random distribution. The rationale for this grouping is given in Janz. ${ }^{7}$

\section{Results}

Relation to seizure types and syndromes

Of the 1044 patients with an unequivocal rating, 103 $\mathbf{( 9 . 9 \% )}$ were photosensitive. Photosensitivity was found mainly in patients whose first EEG was recorded between the ages of 10 and 25 years (fig). The age at onset of their epilepsy (mean 14.4) was lower than that of non-photosensitive subjects in general but did not differ from that of non-photosensitive patients with epileptic EEG discharge (table 1).

Three fifths of the photosensitive persons were females in contrast to the opposite sex ratio in the other patients (table 2).

Eighty-eight percent of photosensitive patients suffered from generalised epilepsies that, otherwise, only slightly prevailed in this material (table 3 ).

When the various syndromes of generalised epilepsy are considered separately, only three of them were significantly related to photosensitivity: childhood absence epilepsy or pyknolepsy, juvenile myoclonic epilepsy, and epilepsy with generalised tonic-clonic seizures on awakening. No significant relation was found with the mostly symptomatic generalised syndromes of early childhood (West and Lennox), with juvenile absence epilepsy (as long as the patients did not have additional myoclonic seizures), or with generalised tonic-clonic seizures in the evening leisure. The most striking difference was that between the two absence syndromes. These have typically different ages of onset that could influence the investigation ages. If this was so, it would in turn influence the rate of photosensitive subjects. From table 4, it can be seen that this is not true: the investigation ages of the absence syndromes are very close although their ages of onset are different.

Table 4 indicates further that the investigation age of non-photosensitive patients was considerably higher than that of photosensitive patients. This, however, is not true for the generalised epilepsies of 
Table 2 Sex ratios of photosensitive and non-photosensitive subjects in whole cohort and syndromes with frequent photosensitivity

\begin{tabular}{lllll}
\hline & Total cohort & $\begin{array}{l}\text { Childhood absence } \\
\text { epilepsy }\end{array}$ & $\begin{array}{l}\text { Juvenile myoclonic } \\
\text { epilepsy }\end{array}$ & $\begin{array}{l}\text { Epilepsy with grand mal } \\
\text { on awakening }\end{array}$ \\
\hline $\begin{array}{l}\text { Photosensitive } \\
\text { Males }\end{array}$ & 42 & 8 & 12 & 13 \\
$\begin{array}{l}\text { Females } \\
\text { Non-photosensitive }\end{array}$ & 61 & 9 & 25 & 22 \\
$\quad \begin{array}{l}\text { Males } \\
\text { Females }\end{array}$ & 571 & 33 & 49 & 130 \\
\hline
\end{tabular}

The different sex ratios of photosensitive and non-photosensitive subjects are significant in whole cohort $(p<0.001)$, juvenile myoclonic epilepsy $(p<0.01)$ and GM on awakening $(p<0.05)$.

Table 3 Photosensitivity and epileptic syndromes

\begin{tabular}{|c|c|c|}
\hline & Photosensitive & Non-photosensitive \\
\hline $\begin{array}{l}\text { (A) Whole cohort } \\
\text { Generalised epilepsies } \\
\text { Localisation-related epilepsies } \\
\text { (B) Syndromes of generalised epilepsy } \\
\text { West and Lennox syndromes } \\
\text { Childhood absence epilepsy } \\
\text { Juvenile absence epilepsy } \\
\text { Juvenile myoclonic epilepsy } \\
\text { (C) Syndromes of grand mal in relation to the sleep-waking cycle } \\
\text { Grand mal on awakening } \\
\text { Evening grand mal } \\
\text { Sleep grand mal } \\
\text { Random grand mal }\end{array}$ & $\begin{array}{r}91(15 \cdot 2 \%) \\
12(2 \cdot 7 \%) \\
7(17 \cdot 1 \%) \\
17(18 \cdot 0 \%) \\
6(7 \cdot 5 \%) \\
37(30 \cdot 5 \%) \\
35(13.0 \%) \\
4(10.0 \%) \\
6(4.4 \%) \\
3(4.6 \%)\end{array}$ & $\begin{array}{c}507(84.8 \%) \\
434(97.3 \%) \dagger \\
34(82.9 \%) \\
77(82.0 \%)^{*} \\
74(92.5 \%) \\
84(69.5 \%) \dagger \\
\\
235(87.0 \%)^{*} \\
36(90.0 \%) \\
131(95.6 \%) \\
62(95.4 \%)\end{array}$ \\
\hline
\end{tabular}

${ }^{*} \mathrm{p}<0.01 ; \uparrow \mathrm{p}<0.001$.

Table 4 Syndromes of generalised epilepsy and age groups

\begin{tabular}{|c|c|c|c|c|c|c|}
\hline Syndromes & $\begin{array}{l}\text { West plus } \\
\text { Lennox }\end{array}$ & $\begin{array}{l}\text { Childhood } \\
\text { absences }\end{array}$ & $\begin{array}{l}\text { Juvenile } \\
\text { absences }\end{array}$ & $\begin{array}{l}\text { Juvenile } \\
\text { myoclonic }\end{array}$ & $\begin{array}{l}\text { Grand mal } \\
\text { on awakening }\end{array}$ & $\begin{array}{l}\text { Evening } \\
\text { grand mal }\end{array}$ \\
\hline $\begin{array}{l}\text { Age of onset in years with SD } \\
\text { Photosensitive subjects } \\
\text { Non-photosensitive subjects }\end{array}$ & $\begin{array}{l}5 \cdot 5 \pm 2 \cdot 9 \\
4 \cdot 5 \pm 3 \cdot 2\end{array}$ & $\begin{array}{l}8.0 \pm 5.2 \\
9.5 \pm 6.0\end{array}$ & $\begin{array}{l}12 \cdot 0 \pm 6 \cdot 5 \\
13 \cdot 8 \pm 7 \cdot 0\end{array}$ & $\begin{array}{l}12 \cdot 6 \pm 4.3 \\
16 \cdot 0 \pm 6.9\end{array}$ & $\begin{array}{l}13.2 \pm 7.3 \\
15.4 \pm 9.0\end{array}$ & $\begin{array}{l}24.3 \pm 16.0 \\
19.6 \pm 9.8\end{array}$ \\
\hline $\begin{array}{l}\text { Photosensitive subjects } \\
\text { Non-photosensitive subjects }\end{array}$ & $\begin{array}{l}15.9 \pm 7 \cdot 1 \\
14.9 \pm 7 \cdot 1\end{array}$ & $\begin{array}{l}16.8 \pm 9.4 \\
29.5 \pm 13.6\end{array}$ & $\begin{array}{r}15 \cdot 5 \pm 4 \cdot 2 \\
28 \cdot 6 \pm 14 \cdot 1\end{array}$ & $\begin{array}{l}23 \cdot 6 \pm 10 \cdot 7 \\
32 \cdot 5 \pm 13 \cdot 2\end{array}$ & $\begin{array}{l}22 \cdot 3 \pm 11 \cdot 4 \\
34 \cdot 2 \pm 13 \cdot 6\end{array}$ & $\begin{array}{l}26.8 \pm 16.0 \\
34.4 \pm 13.1\end{array}$ \\
\hline
\end{tabular}

infancy and preschool age, whose investigation age for both subgroups roughly coincided with the age in which photosensitivity is most prominent.

Sex ratios for photosensitive and nonphotosensitive subjects were different in the various syndromes but with one exception: in childhood absence epilepsy, a syndrome with female preponderance, the sex ratio in both groups was identical (table 2).

The 12 patients with focal seizures who were photosensitive are not quite a homogeneous group (table 5). Eight of them were diagnosed as epilepsy with generalised and focal features as their EEGs presented patterns of generalised epilepsy in spite of the focal seizures, and sometimes additional focal EEG findings; three of these have also generalised seizures (absences or myoclonic and astatic). Then, there are three patients whose photosensitivity presumably was not constitutional but provoked by withdrawal of drugs (phenobarbitone, clonazepam, carbromal). Here, photosensitivity was only found once, immediately following drug withdrawal, in contrast to as many as 10-20 previous and later EEGs without any signs of photosensitivity.

In the one remaining patient, a seizure was recorded in the unprovoked EEG. It started with visual hallucinations followed by a tonic versive movement of the head to the left. In the EEG, it began with a right parietal rhythmic activity.

In not less than five of the photosensitive patients with focal seizures, these were versive with visual hallucinations (three simple phosphenes, two complex such as the face of a witch or a skull) or consisted of one of these symptoms. 
Table 5 Photosensitivity and focal seizures

\begin{tabular}{llllr}
\hline Seizure type & Drug withdrawal & Generalised EEG patterns & Parieto-occipital focus & $N$ \\
\hline Complex focal & 2 & $3(1)$ & 0 & 5 \\
Versive/visual & 1 & $3(1)$ & 1 & 5 \\
Other & 0 & $2(1)$ & 0 & 1 \\
& 3 & $8(3)$ & 1 & 12 \\
\hline
\end{tabular}

Parenthesis: patients with additional generalised minor seizures.

Table 6 Seizures observed during EEG investigation

\begin{tabular}{llcc}
\hline Seizure type & During photic stimulation & $\begin{array}{l}\text { In photosensitive patients } \\
\text { outside photic stimulation }\end{array}$ & In non-photosensitive patients \\
\hline Bilateral myoclonus & 25 & 2 & 9 \\
Palpebral myoclonus* & 4 & 2 & 14 \\
Absence & 9 & 14 & 46 \\
Generalised tonic-clonic & 8 & 1 & 7 \\
Simple focal & 0 & 2 & 6 \\
Complex focal & 0 & 2 & 9 \\
\hline
\end{tabular}

* Presumably absences with mild clonic components but not rated as such because responsiveness was not tested.

Table 7 Photosensitivity and findings in the unstimulated EEG

\begin{tabular}{|c|c|c|c|}
\hline$E E G$ finding & Photosensitive subjects & Non-photosensitive subjects & $p<$ \\
\hline $\begin{array}{l}\text { Slow - spike wave* } \\
\text { Spike-wave } \\
\text { Poly - spike-wave } \\
\text { Bilateral epileptic discharge }\end{array}$ & $\begin{array}{l}0 \\
61(25 \%) \\
29(50 \%)\end{array}$ & $\begin{array}{l}26 \\
184(75 \%) \\
29(50 \%)\end{array}$ & $\begin{array}{l}0.01 \\
\text { ns } \\
0 \cdot 001\end{array}$ \\
\hline $\begin{array}{l}\text { - generalised } \\
\text { - more restricted }\end{array}$ & $\begin{array}{l}80(33 \%) \\
22(15 \%)\end{array}$ & $\begin{array}{l}163(67 \%) \\
128(85 \%)\end{array}$ & 0.001 \\
\hline $\begin{array}{l}\text { Regional accentuation of bilateral discharge } \\
\text { - frontal } \\
\text { - temporo-parietal } \\
\text { - occipital } \\
\text { Focal abnormalities of any kind }\end{array}$ & $\begin{array}{r}21(15 \%) \\
7(9 \%) \\
48(70 \%) \\
6(2 \%)\end{array}$ & $\begin{array}{r}120(85 \%) \\
71(91 \%) \\
21(30 \%) \\
252(98 \%)\end{array}$ & $\begin{array}{l}0.001 \\
0.001\end{array}$ \\
\hline
\end{tabular}

*Spike-waves slower than $3 \mathrm{~Hz}$ in the absence of more rapid patterns in the same patient.

\section{Seizures during photic stimulation}

In 46 of the 103 photosensitive patients, not only epileptic EEG discharges but also clinical seizures were precipitated (table 6). With few exceptions, owing to problems with the technical outfit, the seizures were recorded by split screen TV with simultaneous EEG. The reliability of classification of recorded seizures in this cohort, is, thus, unusually high.

The most common seizure type with photic stimulation was the one that is characteristic for juvenile myoclonic epilepsy: bilateral, arrhythmic myoclonic seizures in clear consciousness and with accentuation in the distal upper extremities. Apart from generalised tonic-clonic seizures, this type was the only one the frequency of which was increased by photic stimulation. Absences were found relatively infrequently and, even in photosensitive patients, were more often observed outside photic stimulation (mostly during hyperventilation). Focal seizures were not registered during photic stimulation.

\section{EEG findings}

The following EEG parameters were considered: background activity, response to visual stimuli, focal slowing, bilateral epileptic discharge (type, frequency, regularity of shape, generalisation or not, local accentuation), and focal epileptic discharge.

Photosensitivity was related to poly-spike wave, to generalised distribution of epileptic discharge and to its occipital accentuation. It was inversely correlated with slow spike waves (if there were no additional more rapid patterns), and to focal findings (table 7).

\section{Discussion}

Some of the basic findings of this study such as age dependency of photosensitivity, its sex ratio and its relation to generalised epilepsy are well-known and indicate comparability of this sample with other studies that reported similar correlations. The rates of photosensitivity of this investigation are probably 
minimal. In all syndrome groups but one the photosensitive patients were on average about 9-12 years younger than the non-photosensitive ones. The investigation ages of the latter are beyond the optimal age for discovering photosensitivity with the stimulation method used here. Then, the patients were, with few exceptions, on medication at investigation. In some patients, pre-existent photosensitivity may have been suppressed by medication. The finding that photosensitivity was correlated with generalised distribution of spike-wave discharge in contrast to a more restricted distribution probably reflects more efficient control of seizures and, perhaps, photosensitivity in the latter.

Only a few photosensitive patients had focal seizures. They all belonged to three somewhat unusual groups: three of them presented signs of photosensitivity only once in a series of EEG investigations, obviously precipitated by withdrawal of some drug, the withdrawal of which is known sometimes to produce such an effect. The second group were patients who presented with both focal and generalised epileptic signs and symptoms. Presumably their photosensitivity was related to the generalised and not the focal aspect of their seizure disorder. Finally, there was a group of patients whose focal seizures were characterised by visual hallucinations or a versive movement of the head or a combination of both. Between this group and the previous one there was, in our material, considerable overlap. The common denominator for photosensitivity and seizures with visual hallucinations is probably dysfunction of the visual cortex which is also indicated by the correlation of photosensitivity with occipital accentuation of spike wave discharge.

To conclude, the relation of photosensitivity to generalised rather than localisation-related epilepsies appears to be even closer than expected, and if there is a correlation with cortical localisation, it seems to be mostly to the occipital cortex. In general, focal EEG signs are even negatively correlated with photosensitivity.

The correlations of the various syndromes of generalised epilepsy with photosensitivity were not uniform, which is an unpredicted finding. For the syndromes of early childhood that are mostly symptomatic epilepsies, no significant correlation was found. This could be a problem of small numbers, as the actual occurrence of photosensitivity in this group is of the same magnitude as in pyknolepsy and epilepsy with grand mal on awakening. It has to be noted, however, that this entire group, unlike the others, was investigated at the peak age of photosensitivity. We have calculated age-related rates of photosensitivity in our whole cohort, and obtained figures of $32.9 \%$ in the age group 11-15 years, and
$15.7 \%$ in the age group 16-20 years. The patients with early childhood syndromes were investigated at $15 \cdot 1 \pm 7 \cdot 1$ years. Thus, their rate of photosensitivity $(17 \cdot 1 \%)$ is not above average age expectancy.

At their onsets, the early childhood syndromes have characteristic EEG patterns: hypsarrhythmia in West's syndrome, and slow spike waves in LennoxGastaut-syndrome. We are not aware of a longitudinal investigation of the evolution of these patterns. It is well-known, however, that EEG investigations of such patients in adolescence and adulthood give different results. Hypsarrhythmia is very rarely found at that age, and was only present in one of our patients. Slow spike waves will often still be present but in many patients together with more rapid spike wave patterns. It was interesting to see that of the 26 of our patients who had only slow spike waves, none was photosensitive. This could indicate that in patients with generalised epileptic syndromes of early childhood, the development of spike wave discharge of $3 \mathrm{~Hz}$ or faster is to some extent a prerequisite for the development of photosensitivity.

Then, no significant correlation was found with the more rare of the two syndromes of generalised epilepsy with generalised tonic-clonic seizures, and generalised tonic-clonic seizures in the evening leisure. Again, however, the actual rate seems somewhat elevated in this patient group that might be too small to reach statistical significance. Two other factors could contribute to a smaller rate of photosensitivity in these patients as compared with generalised tonicclonic seizures on awakening. The age of onset of evening epilepsy is later than of awakening epilepsy, and beyond the peak age for photosensitivity. This age difference is not significant in our material but has been observed previously in another study ${ }^{8}$ where it was significant. Then, there was, in our patients with this syndrome, a preponderance of male patients who are less prone to photosensitivity. Thus, a decreased rate of photosensitivity in this group may be secondarily dependent on other characteristics of this entity which perhaps is no syndrome of its own but rather a subvariety of awakening epilepsy. ${ }^{\text {? }}$

The most remarkable finding was the difference between the two absence syndromes when patients with additional myoclonic seizures had been excluded. Childhood absences are clearly correlated with photosensitivity. There is, however, one remarkable difference from other syndromes: here, the sex distribution of photosensitive and non-photosensitive subjects is identical whereas, elsewhere, photosensitivity is more frequent in females. Childhood absence epilepsy is the only important syndrome of generalised epilepsy with female preponderance. It is concluded that it could be the same factor that causes female preponderance in both childhood absence epi- 
lepsy and photosensitivity. This unknown factor could be responsible for the relation of both.

Surprisingly, no correlation with photosensitivity could be demonstrated in juvenile absence epilepsy. This difference is not explained by different investigation ages. The finding has to be contrasted with juvenile myoclonic epilepsy which had the highest rate of photosensitivity of all epileptic syndromes in spite of a relatively late investigation age. Both these syndromes become manifest at approximately the same age. The hypothesis is tempting that photosensitivity is a pathoplastic factor. In the manifestation of generalised idiopathic epilepsy with minor seizures around puberty, the presence or absence of photosensitivity could be decisive for the seizure type that develops. This hypothesis is further supported by our finding concerning the seizure types precipitated by photic stimulation and video documented. Apart from generalised tonic-clonic seizures, myoclonic seizures of the type characteristic for juvenile myoclonic epilepsy was the only seizure type that was unequivocally increased by exposure to light flashes. Absences were, even in photosensitive subjects, observed more often without photic stimulation. As photic stimulation accounts for only about one tenth of the whole EEG investigation, this finding must not be over-estimated. Thus, a possible conclusion that photic stimulation may inhibit absences, for example by an increase of vigilance, cannot be based on these figures.

The close correlation with the typical seizure of juvenile myoclonic epilepsy, however, is beyond doubt. In addition, the correlation of photosensitivity with the typical EEG pattern of this syndrome, polyspike should be mentioned.

Photosensitivity is generally considered as a genetically determined phenomenon. ${ }^{14}$ The existence of symptomatic forms is doubtful in spite of the conspicuous frequency of photosensitivity in some disorders with myoclonias such as the Ramsay Hunt syndrome or Lafora's disease. ${ }^{910}$ Could the photosensitivity of juvenile myoclonic epilepsy be a symptomatic form connected with the myoclonias?
Phenomenologically it does not differ from photosensitivity in other patients. The sex ratio of photosensitive patients with juvenile myoclonic epilepsy contradicts a symptomatic form as it is the same as in other photosensitive subjects and different from non-photosensitive patients with juvenile myoclonic epilepsy. However, a genetic study is desirable of the kind of Doose's study on absences and photosensitivity $^{1}$ which revealed that the photosensitivity genetics of these patients are separate from the genetics of epilepsy.

\section{References}

1 Doose H. Photosensitivity: Genetics and Significance in the Pathogenesis of Epilepsy. In: Anderson VE, Hauser WA, Penry JK, Sing CF, eds. Genetic Basis of the Epilepsies. New York: Raven, 1982:113-21.

2 Jeavons PM, Harding GFA. Photosensitive Epilepsy. London: Heinemann, 1977.

3 Rabending G, Klepel H. Die Fotostimulation als Aktivierungs methode in der Elektroenzephalographie. Jena: Fischer, 1978.

4 Newmark ME, Penry JK. Photosensitivity and Epilepsy. A Review. New York: Raven, 1979.

5 Bickford RG, Sem-Jacobsen CW, Whithe PT, Daly DD. Some observations on the mechanism of photic and photo-metrazol activation. Electroencephalogr Clin Neurophysiol 1952;4:275-82.

6 Commission on Classification and Terminology of the International League Against Epilepsy. Proposal for classification of epilepsies and epileptic syndromes. Epilepsia 1985;26:268-78.

7 Janz D. The grand mal epilepsies and the sleeping waking cycle. Epilepsia 1962;3:69-109.

8 Helmchen $H$. Beitrag zur konstitutionellen Differenzierung im Bereich genuiner Epilepsien. $J$ Neurol 1958;178:541-82.

9 Heycop ten Ham MWv. Lafora disease. In: Vinken PJ, Bruyn GW, eds. Handbook of Clinical Neurology. Vol. 15. Amsterdam: North-Holland, 1974:382-422.

10 Radermecker J. Epilepsy in the degenerative diseases. In: Vinken PJ, Bruyn GW, eds. Handbook of Clinical Neurology, Vol. 15. Amsterdam: North Holland, 1974:325-72. 